\title{
Endozoochory of the same community of plants lacking fleshy fruits by storks and gulls
}

\author{
Víctor Martín-Vélez ${ }^{1}$ (D) | Ádám Lovas-Kiss ${ }^{2}$ (D) | Marta I Sánchez ${ }^{3}$ (D) | Andy J Green ${ }^{1}$
}

${ }^{1}$ Department of Wetland Ecology, Estación Biológica de Doñana, CSIC, Sevilla, Spain

${ }^{2}$ Department of Tisza River Research, Wetland Ecology Research Group, MTA Centre for Ecological Research, Danube Research Institute, Debrecen, Hungary

${ }^{3}$ Departamento de Biología Vegetal y Ecología, Facultad de Biología, Universidad de Sevilla, Sevilla, Spain

\section{Correspondence}

Víctor Martín-Vélez, Department of Wetland Ecology, Estación Biológica de Doñana, CSIC, Américo Vespucio 26, 41092 Sevilla, Spain.

Email: victormartin_velez@hotmail.com

\section{Funding information}

Becas "La Caixa-Severo Ochoa 2016" (VMV). Ministerio de Economía, Industria y Competitividad project CGL2016-76067-P (AEI/FEDER, EU)(MIS, AJG). János Bolyai Research Scholarship of the Hungarian Academy of Sciences, New National Excellence Programme of the Ministry of Innovation and Technology ÚNKP-19-4DE-172. NKFIH OTKA FK-127939 and KH129520 grants (ÁLK).

Co-ordinating Editor: John Morgan

\begin{abstract}
Aims: Research into the dispersal of plants lacking a fleshy fruit by avian endozoochory remains limited, particularly regarding the different roles of specific vectors in the same habitat.

Methods: We compared plants dispersed by endozoochory between two migratory waterbirds differing in body size: the lesser black-backed gull Larus fuscus, and the white stork Ciconia ciconia. We collected faeces and pellets from roosting flocks on dykes in rice fields in Doñana, SW Spain, and extracted intact seeds.

Results: We recovered 424 intact seeds from excreta, representing 21 plant taxa, 11 of which germinated under laboratory conditions. Eight plant species are considered weeds, four of them as alien species, and only two have a fleshy fruit. Seed abundance and species richness per sample did not differ between storks and gulls. Toadrush (Juncus bufonius) was the dominant species, accounting for $49 \%$ of seeds recovered. PERMANOVA and mvabund analyses revealed no differences in the proportions of each plant species dispersed by the two vectors, and seasonal variation in abundance was absent. Overall, germinability was $19 \%$, and declined with increasing delay between sample collection and processing. Transects along dykes identified 52 plant taxa, only 18 of which were recorded in excreta.

Conclusions: Overlap in the communities of non-fleshy-fruited plants dispersed by two unrelated birds of different size suggests that waterbird plant dispersal networks are different from frugivore networks. Unlike for frugivores, decoupling between seed production and ingestion reduces seasonal variation in endozoochory rates. For Juncus bufonius and other plants, these avian vectors provide maximum dispersal distances several orders of magnitude greater than predicted from their dispersal syndromes. Endozoochory by migratory waterbirds has major implications for plant distributions in a rapidly changing world, and more research is required before we can predict which plants disperse regularly via this mechanism.
\end{abstract}

\section{KEYWORDS}

Ciconia ciconia, dispersal syndromes, faeces, Juncus bufonius, Larus fuscus, pellets, rice fields, seeds, weeds 


\section{1 | INTRODUCTION}

Dispersal is a crucial determinant of plant distribution, demography and genetic structure (Vekemans and Hardy, 2004; Caughlin et al., 2014), and therefore of plant responses to environmental perturbations, including anthropogenic land use change and climate change (Thuiller et al., 2008; Corlett and Westcott, 2013; Tamme et al., 2014). Moreover, dispersal ecology is central to the spread and potential control of alien plants and weeds (Gosper et al., 2005).

There are still knowledge gaps in our understanding of plant dispersal, including a need for a better characterization of dispersal vectors (Bullock et al., 2017). Many studies have relied on the classifications of plant species into syndromes based on seed morphology to make predictions about vectors, and about dispersal distance (Thomson et al., 2010; Tamme et al., 2014). Animal vectors generally provide the longest dispersal distances for angiosperms (Bullock et al., 2017), yet dispersal syndromes assume that only plants with a fleshy fruit are dispersed by endozoochory (i.e. gut passage). However, repeated empirical studies have shown that this assumption is invalid (Costea et al., 2019; van Leeuwen et al., 2020).

Migratory waterbirds act as dispersal vectors for a broad variety of angiosperms (Green et al., 2016; Costea et al., 2019). In Europe, hundreds of non-fleshy-fruited angiosperm species previously assigned to other syndromes have now been shown to be dispersed regularly by ducks and shorebirds via endozoochory (Soons et al., 2016; Lovas-Kiss et al., 2018a, 2019). Nevertheless, only a handful of detailed studies of waterbird endozoochory exist, compared to the extensive literature on plant dispersal by frugivorous birds (Wenny et al., 2016).

Consequently, basic questions remain unanswered, such as whether there are specialised dispersal relationships between specific waterbird and plant species, or how the considerable range of body size and morphology amongst waterbird groups influences plant dispersal. It is well established that larger frugivores disperse plants with larger fruits (Jordano, 1995; Falcón et al., 2020) and that different bird species have different roles in plant-frugivore interactions (Tsunamoto et al., 2020). In contrast, for non-fleshy-fruited plants at a global scale, larger animals tend to ingest smaller seeds, and a higher number of plant species (Chen and Moles, 2015).

Over the past century, the extent of natural wetlands across the globe has been greatly reduced, whereas that of artificial environments such as rice fields has greatly increased (Davidson et al., 2018). Many waterbird species have shifted their habitat use and movement patterns to take advantage of agricultural environments such as rice fields, which are now important for waterbirds across the world (Rendón et al., 2008; Toral and Figuerola, 2010; Sesser et al., 2018). During the harvest period, food availability peaks and rice fields can support high numbers and diversities of waterbirds (Rendón et al., 2008; Toral et al., 2011; Sesser et al., 2018), which can disperse plants from the seed bank (Powers et al., 1978), which is particularly diverse for weeds (Chauhan et al., 2010). Within rice fields, it is therefore possible to investigate the essential differences in seed dispersal between different plant vectors feeding in the same habitat.

Studies regarding the role of waterbirds as plant vectors within rice fields are scarce (Powers et al., 1978; Brochet et al., 2010). Waterbirds feed on the alien red swamp crayfish (Procambarus clarkii) in Iberian rice fields, and there is evidence for secondary dispersal of seeds carried on the outside of the crayfish by lesser black-backed gulls (Larus fuscus) (Lovas-Kiss et al., 2018b). The white stork (Ciconia ciconia) is a much larger waterbird also known to feed on crayfish within rice fields (Tablado et al., 2010), but its role in endozoochory is unknown. Both these species are benefitting from the expansion of artificial habitats, and can show high functional connectivity between different habitat types (Bécares et al., 2019; Martín-Vélez et al., 2020), increasing their potential as plant vectors.

In this study, we compared endozoochory by these two omnivorous waterbirds in rice fields. We identified and quantified intact seeds through faecal and pellet analyses, and evaluated their germinability. Our specific objectives were: (a) to establish how plant dispersal interactions differ between these two different birds, and determine the roles of diet and seasonal variation; (b) to evaluate the traits and life history strategies of the plants dispersed, including whether they were alien species or agricultural weeds; and (c) to compare the plant species dispersed by these birds with the vegetation where seeds are egested, by carrying out transects along rice field borders, and comparing traits between plants recorded and those dispersed.

\section{2 | METHODS}

\section{1 | Study area and study species}

The rice fields of the Guadalquivir delta $\left(37^{\circ} 7^{\prime} 50^{\prime \prime} \mathrm{N}, 6^{\circ} 9^{\prime} 54^{\prime \prime} \mathrm{W}\right.$, SW Spain, Figure 1), flooded from May to January, are the largest rice field complex (37,000 ha) in Spain and an important part of the Doñana wetland complex (Green et al., 2018). These rice fields support a diverse avifauna (Rendón et al., 2008; Toral and Figuerola, 2010). We selected two model bird species owing to their high abundance, major difference in morphology, and the ease with which their excreta could be collected.

The lesser black-blacked gull (LBBG) is a wintering migratory waterbird breeding in northern Europe (Baert et al., 2018). LBBG typically arrive in SW Spain in September and migrate back to their breeding grounds in March (Rendón et al., 2008; Klaassen et al., 2012). The white stork breeds from northern Europe to West Africa with major differences in migration patterns between populations, and the Doñana rice fields hold a mixture of residents and winter migrants (Flack et al., 2016; Bécares et al., 2019). Both species have increased across Europe and in the study area in recent decades (Rendón et al., 2008; Ramo et al., 2013; Wetlands International, 2020). The increases in numbers are related with increased food availability, largely from landfills and rice fields (Massemin-Challet et al., 2006; Ramo et al., 2013; Martín-Vélez et al., 2020). Over 10,000 LBBG and over 1,000 white storks were present in the 
FIGURE 1 Location of sites within the rice fields of Doñana Biosphere Reserve where gull and stork samples (including pellets and faeces) were collected, and vegetation transects were monitored, in 2016 and 2017

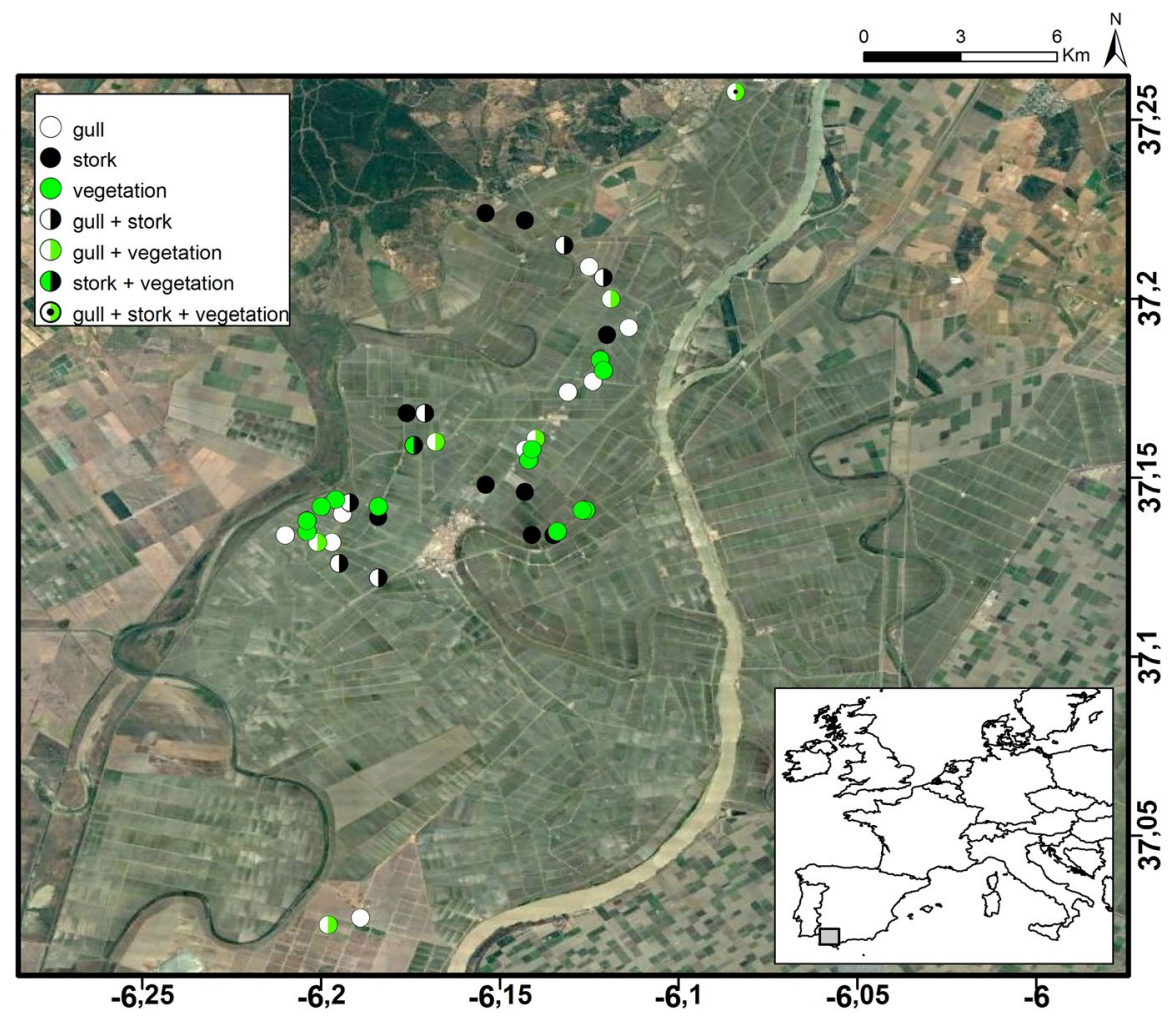

TABLE 1 Numbers and fresh mass in grams [reported median values and interquartile range (IQR) in parentheses] of samples collected in rice fields from white stork and lesser black-blacked gull (LBBG)

\begin{tabular}{|c|c|c|c|c|c|c|c|}
\hline Species & $\begin{array}{l}\text { Sample } \\
\text { type }\end{array}$ & $\begin{array}{l}\text { Median } \\
\text { mass (IQR) }\end{array}$ & $\begin{array}{l}\text { Nov. } \\
2016\end{array}$ & $\begin{array}{l}\text { Sept. } \\
2017\end{array}$ & $\begin{array}{l}\text { Oct. } \\
2017\end{array}$ & $\begin{array}{l}\text { Nov. } \\
2017\end{array}$ & Total \\
\hline \multirow[t]{2}{*}{ White stork } & Faeces & $2.55(0.54)$ & 51 & 32 & 23 & 30 & 136 \\
\hline & Pellets & $8.0(0.01)$ & 22 & - & 14 & 11 & 47 \\
\hline \multirow[t]{2}{*}{ LBBG } & Faeces & $2.0(0.55)$ & 53 & 42 & 47 & 41 & 183 \\
\hline & Pellets & $8.2(0.06)$ & 25 & 15 & 27 & 30 & 97 \\
\hline
\end{tabular}

Doñana rice fields during our study. Mean body mass is $762 \mathrm{~g}$ for LBBG and 3,345 g for white stork (Wilman et al., 2014).

\subsection{Excreta collection}

A total of 463 excreta samples were collected in 36 different locations around the rice fields to the northeast of Doñana National Park (Figure 1). In all, 183 samples (136 faeces and 47 regurgitated pellets) were collected from white stork and 280 (183 faeces and 97 pellets) from LBBG during two consecutive winters: (a) November 2016 and (b) September, October and November 2017 (Table 1). Fresh faeces and pellets were collected from dykes that serve as field borders and public access routes, where monospecific flocks were resting after feeding in the fields (no feeding was observed on dykes). Samples were taken from points separated by at least $1 \mathrm{~m}$ to ensure they were from different individuals. To avoid contamination, we removed the surface in contact with the soil with a knife before storing the samples in separate zip bags. We preserved the samples in the fridge at $4^{\circ} \mathrm{C}$ until analysis. Average storage time was 35 days (range 4 to 80 ).

\section{3 | Description of local flora along the dykes}

Twenty vegetation transects were selected opportunistically to determine the most representative flora of the dykes in the rice field complex (Figure 1). Ten transects were carried out during February 2017 and ten in September-October 2017 in order to account for seasonal differences. We identified all taxa present in the transects along a straight line of $100 \mathrm{~m}$ along the dykes, including moist soil and aquatic plants along the rice field borders. We did not sample vegetation within the rice fields, where gulls and storks were feeding, because we were unable to get permission to do so.

\section{4 | Sample processing}

The fresh mass of pellet and faecal samples was first measured on a balance (Sartorius MSE225P) (Sartorious Lab Instruments, Goettingen, Germany). Diet composition based on the main food 
items present was categorized as: (a) crayfish-based; (b) rice-based; or (c) mixed (presence of both rice and crayfish). Samples were then sieved (100 $\mu \mathrm{m}$ mesh) and inspected under a stereomicroscope in Petri dishes. Plant diaspores (seeds and oogonia; "seeds" from hereon) were then retrieved, counted, photographed and measured (with ZEN 2-2.0 software) (Carl-Zeiss, Oberkochen, Germany). We identified them to the lowest taxonomic level by comparing the shape, size and seed coat pattern with available literature (Benedí and Orell, 1992; Castroviejo, 1998; Bojnanský and Fargašová, 2007; Cappers et al., 2012). When it was not possible to assign a morphotype to species level with certainty, genus or family level was reported. We did not include rice grains (Oryza sativa) as seeds dispersed because they were unlikely to be viable (Cummings et al., 2008). Immediately after retrieval, intact seeds were placed in Petri dishes that contained bacteriological agar, and placed in germination chambers with a $12 / 12$ photoperiod and $22^{\circ} \mathrm{C} / 18^{\circ} \mathrm{C}$ temperature conditions. Germination tests lasted for three months and seeds were checked every day for germination. Once germinated, seeds were counted and removed from the Petri dish. Seeds infected with fungi were also removed and considered not germinated.

\section{5 | Statistical analyses}

To evaluate the sampling effect on taxon richness within the samples, we carried out rarefaction analyses for each study species and sample type (Sanders, 1968), using the R package iNEXT for rarefaction analyses (Hsieh et al., 2016). We applied non-metric multidimensional scaling (NMDS) and PERMANOVA analyses (applying Bray-Curtis for distance matrices) to identify differences in community composition between samples using the metaNMDS and adonis functions in the vegan R package (Oksanen et al., 2010).

Abundance and richness (per sample) of seeds were compared between sample types (faeces or pellets), species (LBBG or white stork), period (November 2016, September 2017, October 2017 and November 2017) and diet (crayfish-based, rice-based or mixed) as fixed factors, using sample weight as a continuous variable and sampling location as a random factor. We used Generalized Mixed Models (GLMM) with negative binomial error distribution and loglink function in the gImmTMB package (Magnusson et al., 2017) to account for the many samples with zero values, and overdispersion. For the dominant species Juncus bufonius, we carried out similar GLMM analyses for abundance, but results were the same as for total seed abundance (details not shown). For Juncus bufonius, we also tested the effect of bird species, sample type, diet, period and storage time on germinability (binomial model) and time (days) until germination (linear model) with the package Ime4 (Bates et al., 2014).

We carried out multivariate negative binomial tests for abundance of the remaining taxa, which was much lower than for Juncus bufonius. These tests included the variables species, sample type, period and diet and were perfomed with the manyg $/ m$ function in the mvabund package (Wang et al., 2012). All analyses were performed with R (v3.3.4 R Core Team, 2018).
We calculated the Jaccard Index (JI) to compare similarities in species composition between excreta samples and vegetation transects (details in Appendix S1 of the supplementary material). We assigned to each taxon found in excreta and/or transects a mean seed weight (from the LEDA traitbase; Kleyer et al., 2008), a dispersal syndrome (from baseflor, Julve, 1998) and an Ellenberg $F$ value (Julve, 1998; Hill et al., 1999). F indicates plant soil moisture preference, and varies from 1 to 12 (e.g. a value of 1 indicates extremely dry soils, whereas 9 indicates wet soils). Finally, to evaluate potential determinants of relative abundance of different taxa within excreta, we tested if abundance was related to seed length or mass (through correlations) and dispersal syndrome (via a Kruskal-Wallis test, with a Dunn test for post-hoc; dunn.test R package, Dinno and Dinno, 2017), or related to the frequency of plants along dykes by correlating with percentage occurrence within transects.

\section{RESULTS}

\subsection{Mass and general content of bird excreta}

On average, excreta samples from storks were heavier than those from gulls (Table 1). These differences were significant for faeces $(U=15,015, P=0.002)$, but not for pellets $(U=2,145, P=0.568)$.

Crayfish remains were recorded in $79 \%$ of stork and $70 \%$ of gull pellets, compared to $93 \%$ of stork and $78 \%$ of gull faecal samples. Rice grains were the next most prevalent food item, and were often combined with crayfish remains. Rice was present in $28 \%$ of stork and $43 \%$ of gull pellets, compared to $24 \%$ of stork and $28 \%$ of gull faecal samples.

\section{2 | Plant seeds recovered from bird excreta}

Overall, 35\% (165 of 464) of excreta samples contained at least one intact seed, and 424 intact seeds from 21 different plant taxa were recorded (Table 2). These included a range of terrestrial, moist soil, and aquatic species, assigned to six different dispersal syndromes and 11 Ellenberg moisture categories (Appendix S2, Figure 2). Eight (38\%) of these 21 taxa are agricultural weeds, and four (18\%) are alien species in Spain (Table 2).

More specifically, $59 \%$ of stork pellets and $45 \%$ of stork faeces contained at least one intact seed, compared to $23 \%$ of gull pellets and $29 \%$ of faeces (Table 2). Nineteen taxa were recorded in stork samples and only 12 in gulls, with 10 taxa (48\% of the total) recorded in both vector species, nine only in storks and two only in gulls (Table 2). The plant community dispersed did not differ significantly between vector species for either pellets (PERMANOVA; $F_{21}=1.18 ; P=0.310$ ) or faeces (PERMANOVA; $F_{21}=0.83, P$ $=0.405$; Table 2, Figure 3). Juncus bufonius was the most abundant taxon in all sample types, representing $49 \%$ of all intact seeds (Table 2). Mean seed length per taxon ranged from $0.4 \mathrm{~mm}$ (Juncus 


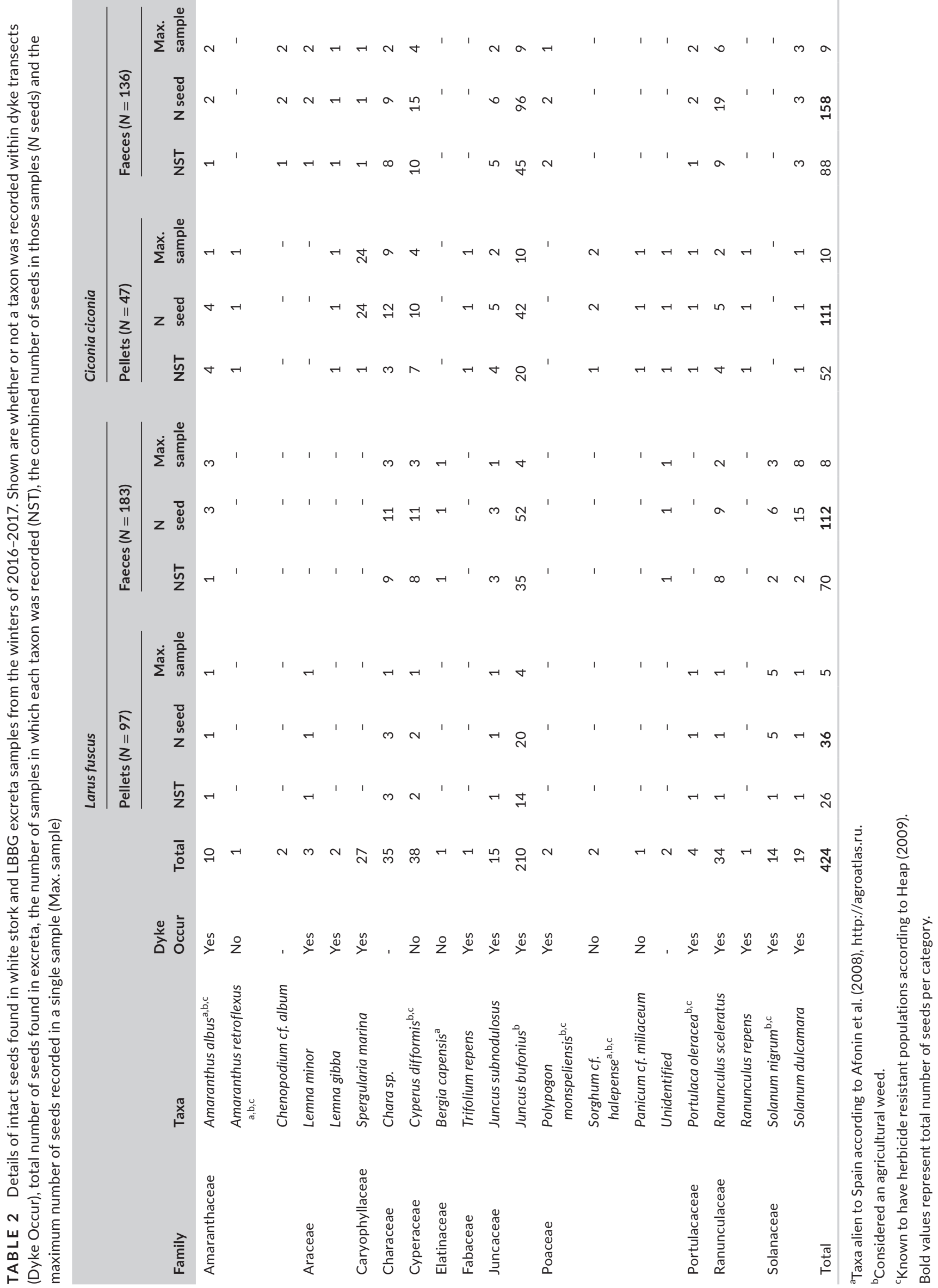


Dispersal syndrome
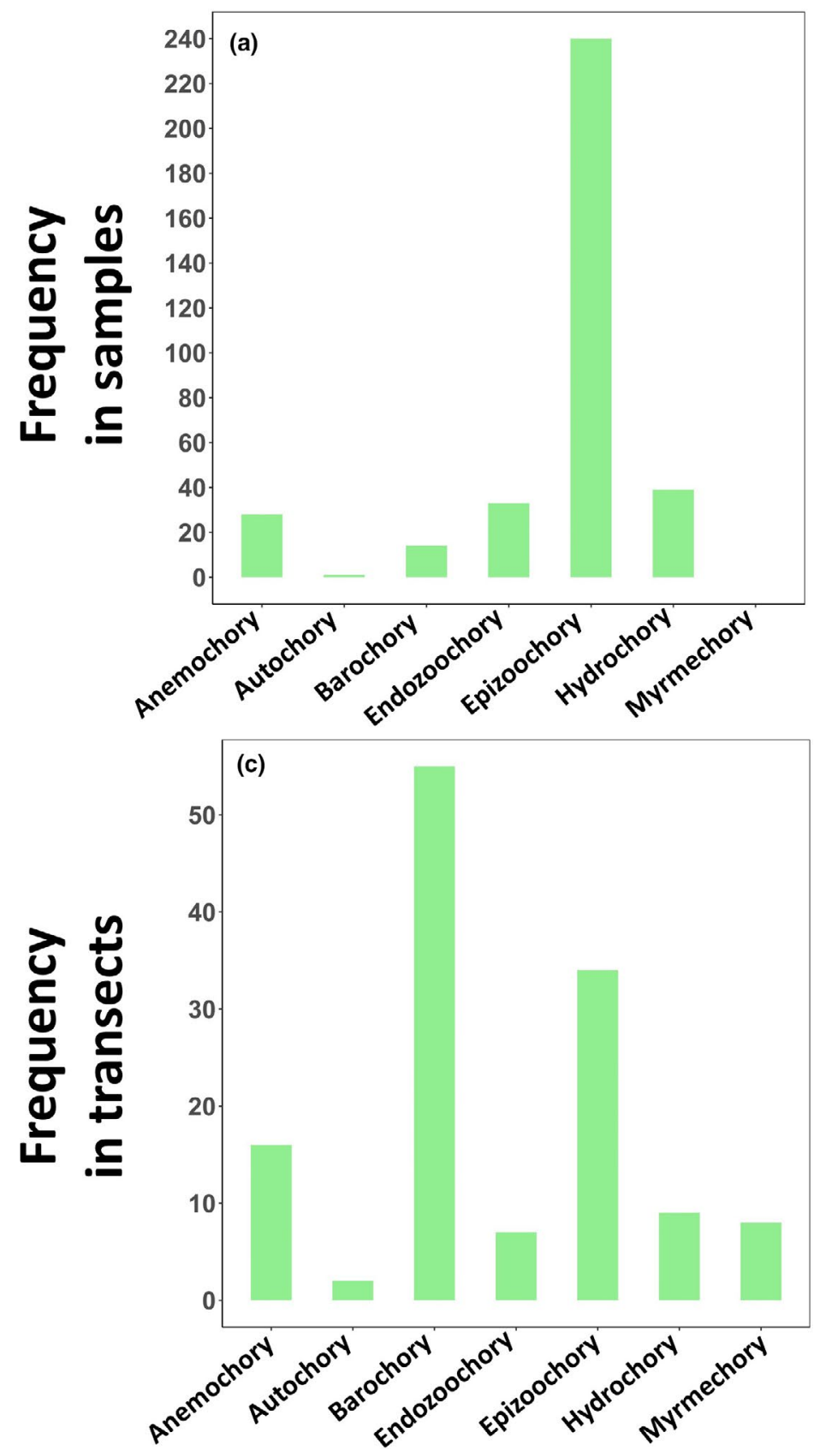

Ellenberg value

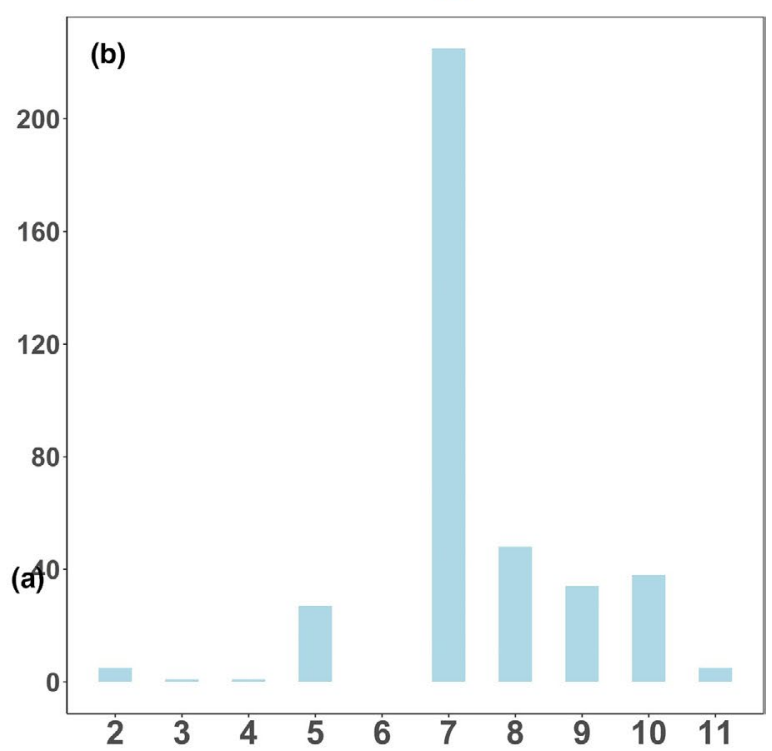

FIGURE 2 Frequency distributions of dispersal syndromes and Ellenberg moisture values based on the abundance of different species. (a, b) Seeds from gull and stork excreta; (c, d) based on the frequency of occurrence in 20 vegetation transects. Juncus bufonius (the dominant taxon in excreta) has an epizoochory syndrome and an Ellenberg value of 7

subnodulosus) to $1.85 \mathrm{~mm}$ (Solanum nigrum). Mean seed length per sample did not vary significantly between bird species $(U=3,239, P$ $=0.819)$ or sample type $(U=2,631, P=0.826)$. Mean seed mass and mean length for a given taxon were significantly correlated $(n=14$, $\left.r_{\mathrm{s}}=0.79 ; P<0.001\right)$. Total abundance of seeds of a given taxon within all excreta samples was significantly correlated with mean mass ( $n=14, r_{\mathrm{s}}=-0.73, P=0.003$ ) but not mean length $(n=21$, $\left.r_{\mathrm{s}}=-0.26, P=0.253\right)$. There were significant differences in the number of seeds from each dispersal syndrome in a given sample $(H=350.22, d f=5,463, P<0.001)$. This was due to significantly greater abundance for epizoochory (to which Juncus bufonius was assigned) than for other syndromes (Figure 2).

Mixed models showed that bird species, sample type and sample mass all had significant partial effects on the total abundance of seeds in samples, as well as on the species richness (Table 3). Neither abundance nor species richness were significantly influenced by 
Faeces

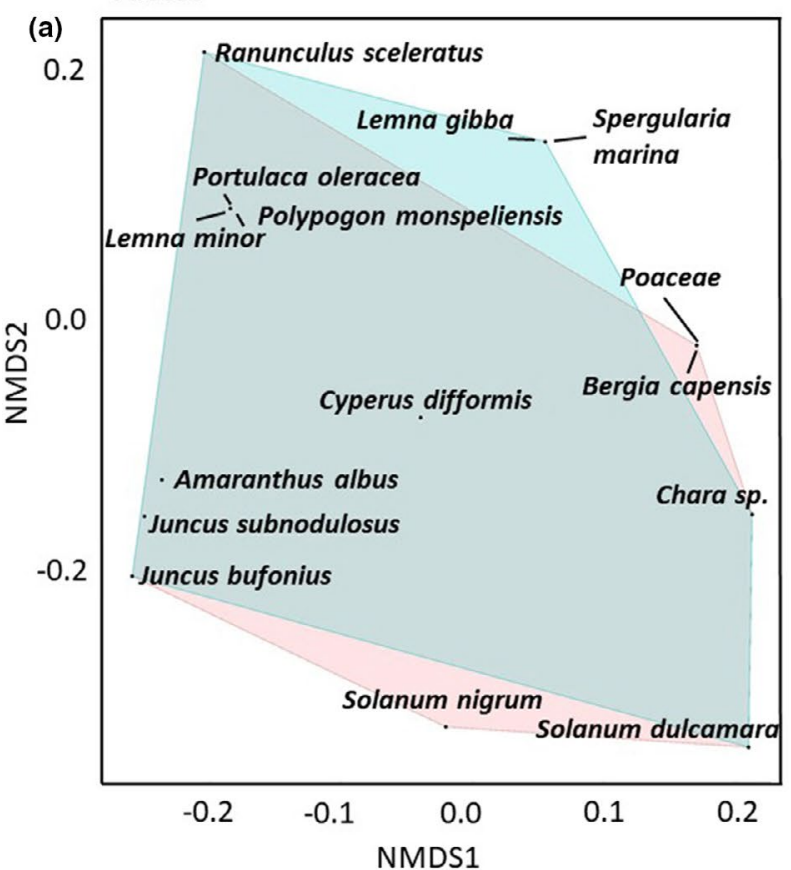

Pellets

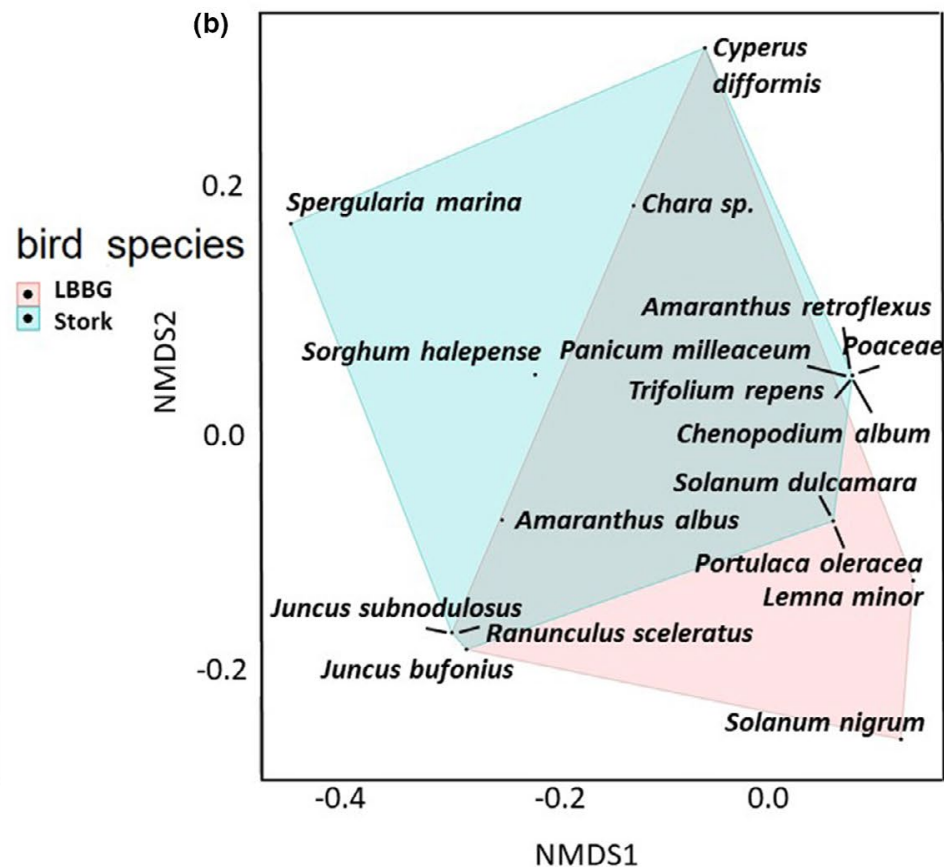

FIGURE 3 Non-metric multidimensional scaling (NMDS) plot showing the relationship between seeds dispersed by lesser black-blacked gull (LBBG) and white stork in faeces (a) and pellets (b) in rice fields

TAB LE 3 Effects of bird species, period, diet, sample type and weight on (A) total abundance of seeds and (B) taxon richness per sample, from negative binomial mixed models

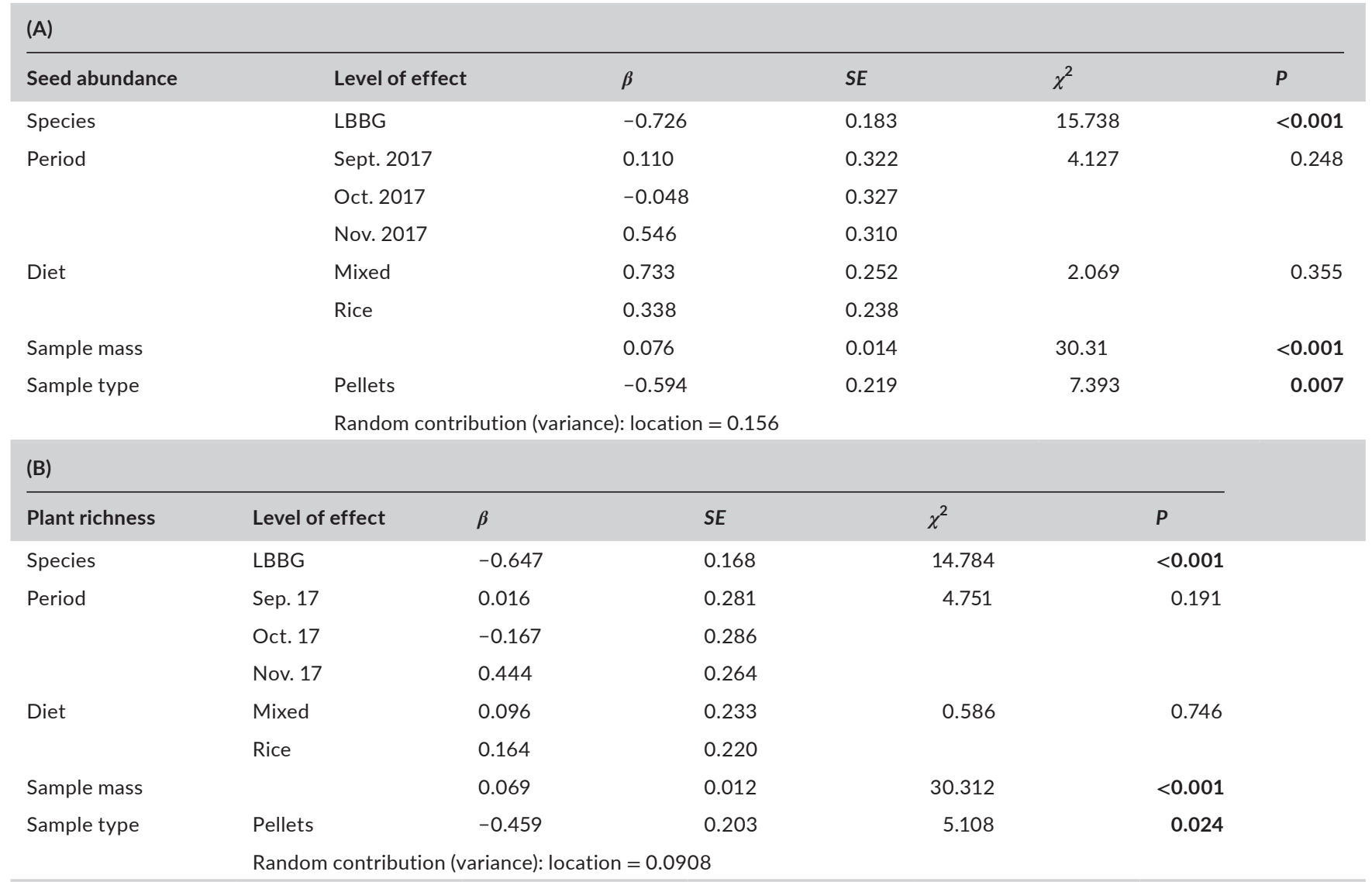

Note: White stork, faecal samples, November 2016, and a diet of crayfish are absent from the table because these levels of the respective factors were aliased, and so effectively had estimates of zero. Sampling location (Figure 1) was included as a random factor. Shown for each term are the parameter estimates $(\beta)$ and their standard errors, and the main effects for each predictor variable. LBBG, lesser black-blacked gull.

Bold values represent total number of seeds per category. 


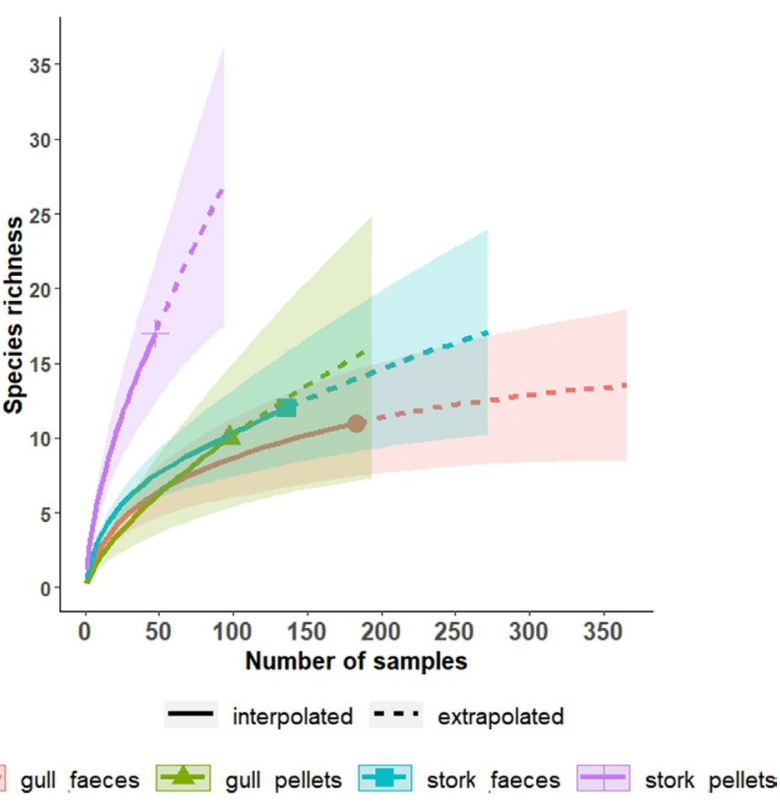

FIGURE 4 Rarefaction analyses showing the accumulated number of plant taxa recorded in pellets and faeces of white stork and lesser black-blacked gull (LBBG), in relation to the number of samples. Error bars represent $95 \%$ confidence intervals

sampling period or the relative content of rice and crayfish in samples (Table 3). Gulls and pellets had significantly fewer seeds and fewer plant taxa per gram of excreta than storks and faeces, respectively (Table 3). When sample mass was removed as a predictor from the models, there was no longer a significant difference in the number of seeds $\left(\chi^{2}=0.085, P=0.77\right)$ or taxa $\left(\chi^{2}=0.254, P=0.61\right)$ between pellets and faecal samples. However, storks still had significantly more seeds and plant taxa per sample than gulls $\left(\chi^{2}=19.6\right.$ $\chi^{2}=20.9$, respectively; $P<0.001$ ).

Rarefaction curves revealed steeper slopes for species richness against sample size for storks than for gulls, particularly for pellets, suggesting that stork pellets contained a higher diversity of seeds (Figure 4). Nevertheless, seed composition analyses with mvabund showed that no plant species was significantly associated with one vector, nor with faeces or pellets (Appendix S3). The only significant effects were seasonal, the probability of finding Ranunculus sceleratus and Cyperus difformis seeds being particularly high in November 2017 (Appendix S3).

\section{3 | Germinability of diaspores from excreta}

Overall, germination was recorded for 11 (52\%) of taxa, with an overall germination rate of $18.9 \%$ (Table 4). For the dominant Juncus bufonius, $19.5 \%$ of seeds germinated, and germinability was significantly affected both by sampling period and the time that excreta samples were stored in the refrigerator before processing (Table 5). Germinability was significantly lower in October 2017 than in November 2016 (posthoc test, $Z=-2.076, P=0.038$ ). The time taken for Juncus bufonius to germinate was also significantly affected by sampling period (Table 5). Germination time was significantly longer in September 2017 than in November 2016 ( $Z=2.436, P=0.022)$.

\section{4 | Relationship with vegetation along dykes}

A total of 52 plant taxa were recorded in 20 vegetation transects (Appendix S3). Overall, 13 of these taxa (26\%) were recorded in excreta (Table 2). Jaccard Index values showed limited similarity between species recorded in transects and excreta (0.19 for LBBG and 0.25 for storks). Juncus bufonius and Conyza canadensis were the taxa recorded most often within transects, and the latter was absent from excreta (Appendix S3). Five species present in excreta were not detected in dyke transects (Table 2 and Appendix S3), including Cyperus difformis, a tall weed abundant within rice stands. There was no correlation between total abundance of seeds per taxon in excreta samples and its frequency of occurrence within transects ( $n=48, r_{s}=-0.15, P=0.298$ ), nor was there any difference in seed mass between taxa unique to transects, unique to excreta, or found in both $(H=4.95, d f=2, P=0.08)$.

Comparisons of syndromes between seeds in excreta and plants in transects (Figure 2) show that the epizoochory syndrome is overrepresented in excreta (representing $68 \%$ of seeds), due to the dominance of Juncus bufonius. In contrast, the barochory syndrome (4\% of seeds) is underrepresented in excreta, and only $9 \%$ of seeds had an endozoochory syndrome. Comparing Ellenberg moisture values between excreta and transects (Figure 2) suggests that 7 (moist soils) is overrepresented in excreta, again due to the dominance of Juncus bufonius. Transects are dominated by dry-soil plants with an Ellenberg value of 2 to 6 ( $77 \%$ of all plant records), uncommon values in excreta (19.5\% of all seeds).

\section{4 | DISCUSSION}

We studied the plant taxa dispersed by a gull and a stork species through endozoochory in an agricultural landscape during three months of the migration and overwintering period. The seeds quantified were dispersed from feeding sites within rice fields to dykes where birds roosted. Most seeds dispersed lacked the fleshy fruit classically linked to avian endozoochory. Our findings add to growing evidence that endozoochory of non-fleshy-fruited plants ("non-classical endozoochory"; Costea et al., 2019) by migratory birds is a widespread ecological process, which is highly important due to its provision of longer dispersal distances than abiotic mechanisms (Viana et al., 2016; Kleyheeg et al., 2019). Our results for storks extend the list of waterbird groups shown to be important vectors for endozoochory, adding to shorebirds, Anatidae and others (Green et al., 2016). The consistency between our results and those for gulls in previous studies (Calvino-Cancela, 2011; Lovas-Kiss et al., 2018b) illustrates how "non-classical endozoochory" can be a predictable process comparable to endozoochory 


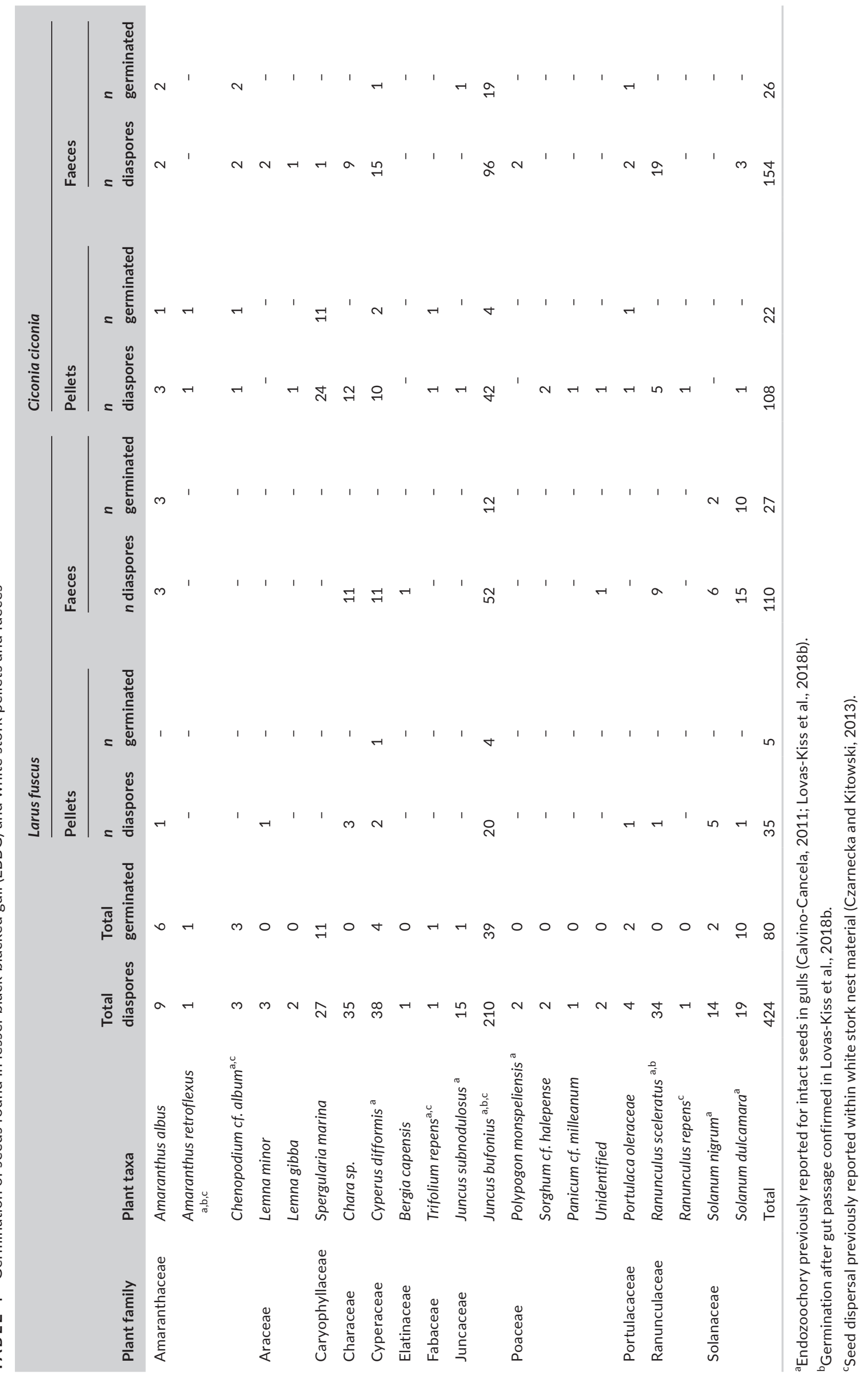


TAB LE 5 Effects of species, period, sample type, diet and storage time on germinability (A) and germination time (B) of Juncus bufonius based on binomial and linear models respectively

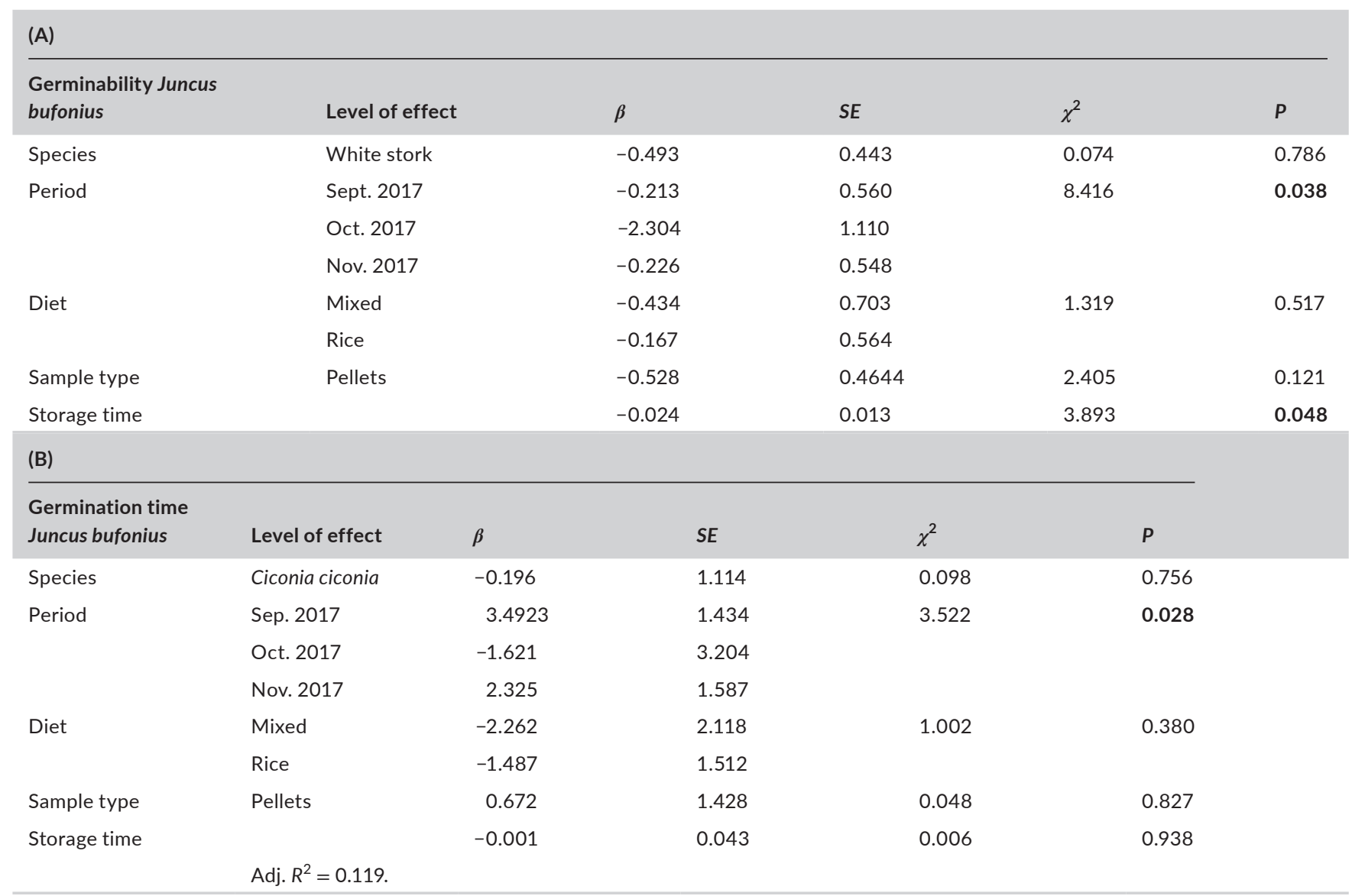

Note: Lesser black-blacked gull (LBBG), faecal samples, November 2016, and a diet of crayfish were aliased. See Table 3 for further explanation. Bold values represent total number of seeds per category.

by frugivores (e.g. dominance of Juncus bufonius among seeds dispersed in rice fields).

On the other hand, we recorded seed dispersal of eight species not previously recorded in gulls or storks, including three alien species, Amaranthus albus, Bergia capensis, and Sorghum halepense. Many of these new taxa were recorded in small numbers, and their detection was subject to sampling error, as illustrated by rarefaction (Figure 4). Therefore, the apparent differences we recorded in the species dispersed by each vector may be purely a result of sampling error, and the number of plant taxa dispersed by the stork and gull populations may be much higher than that detected. We confirmed that $52 \%$ of the plant taxa found can germinate after gut passage, an underestimate given the small sample size $(n \leq 3)$ of the angiosperm species that failed to germinate (Table 4; Ranunculus sceleratus was an exception).

Lovas-Kiss et al. (2018b) found evidence that seeds dispersed by LBBG within rice fields were ingested involuntarily when feeding on crayfish, which have small seeds stuck on the outside. Given the small size of the seeds we recorded and the negative correlation between abundance and seed mass, it seems unlikely that gulls or storks would be actively foraging on them. However, diet content (rice vs. crayfish) did not influence the abundance and richness of seeds in our samples, suggesting that birds also ingest seeds when feeding on rice within the mud of harvested fields. The Solanum spp. we recorded are likely to be an exception, as these plants grow along the dykes and have berries that may be ingested actively, especially by gulls (Calvino-Cancela, 2011).

Egestion via faeces represents the main form of endozoochory in our study system. Storks produce four times more faeces than pellets in dry mass per day (Kwieciński et al., 2006). Faeces are also egested in a greater diversity of microhabitats, including feeding sites as well as during flight, whereas pellets may only be egested in roosting sites.

\subsection{Differences between storks and gulls as vectors}

Plant community analyses did not detect overall differences between the two bird species. This suggests a high degree of functional redundancy in their role as vectors, although there are differences in their movement and migration patterns (e.g. storks breed in SW Spain). In our case, in contrast to frugivore studies, avian body mass was not a trait determining dispersal interactions (Chen and Moles, 2015; Costa-Pereira et al., 2018; see also Sebastián-González et al., 
2020). Storks weigh four times more than gulls and have a much wider gape, yet we found no difference in the size of seeds dispersed. Mean seed length of the plant taxa dispersed was $0.86 \mathrm{~mm}$ ( \pm 0.08 SE, range $=0.4-1.85 \mathrm{~mm}$ ), showing a strong representation of small seeds. Taxa with relatively smaller and relatively harder seeds are more likely to survive passage through the avian gut (Reynolds and Cumming, 2016; Lovas-Kiss et al., 2020). Although harder and/or large food items (including large seeds) are more likely to be egested in pellets than in faeces (Sánchez et al., 2005; LovasKiss et al., 2019), we found no difference in seed size between these two forms of excreta, presumably owing to the generally small and similar size of all seeds.

Per individual, the larger storks ingest more, egest more, and disperse more seeds a day than gulls. However, LBBGs are about ten times more abundant than white storks within the rice fields (Rendón et al., 2008). Bearing in mind the peak numbers of gulls and storks counted (Estación Biológica de Doñana monitoring data), and estimates for daily production of excreta (Martín-Vélez et al., 2019), in the order of $10^{5}$ intact seeds per day are dispersed within the rice field complex (including both fields and dykes) by these two bird species alone at peak periods. In the case of LBBG, about $8 \%$ of seeds are dispersed beyond the rice field complex into other habitats over distances of up to $150 \mathrm{~km}$ (Martín-Velez , 2021).

The lack of a difference between storks and gulls in plants dispersed suggests that other birds of an intermediate size (e.g., herons, egrets, glossy ibis, other gulls) that are abundant in rice fields and feed in a similar manner on crayfish (Tablado et al., 2010) may be vectors for the same plant species. On the other hand, other birds such as ducks, shorebirds and greater flamingos have different feeding strategies, and may disperse plants represented in rice field seed banks in different proportions.

\subsection{Comparison between seeds dispersed and vegetation transects}

Endozoochory by storks or gulls was only recorded for $26 \%$ of the plant taxa from transects along dykes. Most of the plant taxa in excreta have high water requirements (Figure 2) and occur within rice stands, but not along the dykes. Vegetation transects were conducted along the dyke habitats where birds roosted, and thus recorded plants with low moisture requirements (e.g. Conyza canadensis, absent from excreta) on the top of dykes (Figure 2) and generalist plants occurring at field edges. However, $73 \%$ of seeds from excreta were from taxa recorded in transects, therefore seeds dispersed to dykes by birds may become established. Some species recorded in excreta have low moisture requirements yet were not recorded in dyke transects (e.g. Sorghum halepense Appendix S2), possibly because they grow in rice fields in their dry phase before they are flooded sometime in May. The vegetation growing in fields during this period, and the composition of the seed bank, should be studied in future to clarify which plant species are preferentially dispersed by waterbirds.

\section{3 | Seasonality}

Different management practices (e.g. harvesting, tilling) may change the availability of different species in the seed bank and of food resources for birds in rice fields (Chauhan et al., 2006; Toral et al., 2011; Li et al., 2012), but we recorded no variation in the species richness and abundance of seeds dispersed by birds over a three-month period. The only seasonal effects were for Ranunculus sceleratus and Cyperus difformis, which showed less abundance in September and October respectively. Both species grow within the rice stands, and perhaps their seed dispersal may be favoured by tilling practices in November. Since storks and gulls are generally dispersing seeds after they have left the mother plant and have entered the seed bank, this decoupling between seed maturity and endozoochory means that differences in phenology between plant species dispersed do not readily translate into differences in the timing of dispersal. Similarly, Brochet et al., (2010) found no seasonal changes in the frequency of endozoochory in teal Anas crecca wintering in the Camargue and feeding partly in rice fields. In contrast, frugivorous birds can show major temporal differences in the proportions of different plants dispersed (Carnicer et al., 2009; Vázquez et al., 2009).

Possibly, much greater variation between months and bird species in plants dispersed would be recorded if excreta were sampled within natural wetlands. Rice fields are more predictable in their flooding patterns and food resources than natural wetlands in Doñana, and there are important differences in the bird communities they hold (Rendón et al., 2008). Likewise, storks resident in Doñana are likely to disperse different plants in different parts of the annual cycle, when they mainly feed in other habitats (Ramo et al., 2013).

\section{4 | Importance of endozoochory for long- distance dispersal}

Storks, gulls and other birds in rice fields regularly move into natural wetlands as well as into different agricultural habitats, facilitating the dispersal of alien species, weeds and other plants between habitats (Ramo et al., 2013; Bécares et al., 2019; Martín-Vélez et al., 2020). The plant species dispersed in our study are found in many other natural and anthropogenic habitats apart from rice fields. For example, Juncus bufonius occurs in various terrestrial habitats such as grasslands (Milotic and Hoffmann, 2016), is a new arrival in Antartica (Cuba-Diaz et al., 2013), and may provide an interesting model for the study of how zoochory influences genetic patterns at different spatial scales. Many of the plants we recorded in excreta samples are agricultural weeds, some of which have herbicide-resistant populations (Table 2), and waterbirds may facilitate their effective dispersal to other habitats beyond rice fields (Farmer et al., 2017; MartínVélez, 2021). Interestingly, five species dispersed in our study were previously reported in Polish agricultural landscapes during seed dispersal by storks into their nests (Table 4, the mechanism could be transfer in the beak as nest material, or via excreta) in a region lacking rice fields. This suggests there is a class of non-fleshy-fruited 
plants (e.g. Juncus bufonius, Amaranthus retroflexus), with an extreme ability to disperse via birds, which is worthy of future research.

Tamme et al. (2014) considered Juncus bufonius, Ranunculus sceleratus and Spergularia marina to have a maximum dispersal distance of 100,35 and $340 \mathrm{~m}$, respectively (via wind dispersal). All three species are dispersed by storks and gulls over much longer distances, illustrating how studies that make macroecological predictions about plant dispersal based on syndromes ignoring non-classical endozoochory (e.g. Thomson et al., 2010; Tamme et al., 2014) are likely to be unreliable. Juncus bufonius is also dispersed by endozoochory by shorebirds (Lovas-Kiss et al., 2019), at least five species of Anatidae (Lovas-Kiss et al., unpublished) and ungulates (Milotic and Hoffmann, 2016). Different authors assigned this taxon to anemochory, hydrochory and epizoochory syndromes (Löve, 1963; Cope and Stace, 1978; Julve, 1998), exemplifying the subjectivity when syndromes are assigned based on seed morphology.

Increasing numbers of both storks and LBBG in SW Spain in recent decades may have facilitated range expansions of plant species and genotypes. LBBG and white stork move at three spatial scales, enabling seed dispersal into a range of habitats: (a) daily movements of up to $20 \mathrm{~km}$ between different feeding and roost sites within the extensive rice field complex, where they often stay for several days at a time (Bouten et al., 2013; Martín-Vélez et al., 2020); (b) between rice fields and other habitats in Andalusia, including other agricultural lands and natural wetlands such as coastal marshes and inland shallow lakes, with direct flights concentrated within a radius of 150 km (Sanz-Aguilar et al., 2015; Martín-Vélez et al., 2020; Martín-Vélez, 2021); and (c) long-distance migratory flights over hundreds of $\mathrm{km}$ to other parts of Europe or Africa. From September to November, many gulls and storks are on passage to Africa (Flack et al., 2016; Baert et al., 2018). Gut retention times for seeds easily allow endozoochory over such distances (Green et al., 2016).

\section{5 | Conclusions and future work}

Even though $92 \%$ of European angiosperms in continental Europe lack a fleshy fruit (Heleno and Vargas, 2015), avian endozoochory studies to date have concentrated on the remaining $8 \%$ (i.e. on frugivores). Our study illustrates the importance of avian endozoochory for other angiosperms within and beyond a wetland landscape. Waterbirds provide maximum dispersal distances for many angiosperms that greatly exceed those predicted from their dispersal syndromes, with major implications for how plants respond to climate change, land use transformation or introductions of alien species.

Studying waterbird-plant dispersal interactions can improve our understanding of community structure, connectivity and distributions of plant species. Effective dispersal also requires that seedlings become established in new habitats, and the potential for such establishment should be investigated. Detailed studies of Juncus bufonius are required to establish how endozoochory influences population genetics and phylogeography. More research is vital to address plant-bird dispersal networks involving larger numbers of waterbird species and families, and in natural habitats (SebastiánGonzález et al., 2020).

\section{ACKNOWLEDGEMENTS}

Support was provided by staff of the Aquatic Ecology Laboratory LEA-EBD and the Remote Sensing Lab LAST-EBD. Census data were provided by Programa de Seguimiento de EBD-CSIC. Logistic and technical support for fieldwork was provided by Doñana ICTS-RBD. Many volunteers contributed to fieldwork.

\section{AUTHOR CONTRIBUTIONS}

VMV collected and analysed the samples, performed data analyses and figures and wrote the first draft; ÁLK identified the plant taxa and reviewed several drafts; MIS reviewed several drafts; AJG contributed with sampling design, and co-wrote advanced drafts. All authors gave their final approval of the document and declare no conflict of interests.

\section{DATA AVAILABILITY STATEMENT}

Datasets used for statistical analyses can be found in the Digital CSIC repository: http://hdl.handle.net/10261/221014

\section{ORCID}

Víctor Martín-Vélez iD https://orcid.org/0000-0002-4846-8177

Ádám Lovas-Kiss iD https://orcid.org/0000-0002-8811-1623

Marta I Sánchez iD https://orcid.org/0000-0002-8349-5410

Andy J Green iD https://orcid.org/0000-0002-1268-4951

\section{REFERENCES}

Afonin, A.N., Greene, S.L. Dzyubenko, N.I. and Frolov, A.N. (Eds.) (2008). Interactive Agricultural Ecological Atlas of Russia and Neighboring Countries. Economic Plants and their Diseases, Pests and Weeds[Online]. Available at: http://www.agroatlas.ru.

Baert, J.M., Stienen, E.W., Heylen, B.C., Kavelaars, M.M., Buijs, R.J., Shamoun-Baranes, J. et al (2018) High-resolution GPS tracking reveals sex differences in migratory behaviour and stopover habitat use in the Lesser Black-backed Gull Larus fuscus. Scientific reports, 8(1), 5391. https://doi.org/10.1038/s41598-018-23605-x

Bates, D., Mächler, M., Bolker, B. and Walker, S. (2014). Fitting linear mixed-effects models using Ime4. arXiv preprint arXiv:1406.5823.

Bécares, J., Blas, J., López-López, P., Schulz, H., Torres-Medina, F., Flack, A., Enggist, P., Höfle, U., Bermejo, A. and De la Puente, J.(2019) Migración y ecología espacial de la cigüeña blanca en España. Monografía n. 5 del programa Migra. SEO/BirdLife. Madrid. https:// doi.org/10.31170/0071

Benedí, C. and Orell, J.J. (1992) Taxonomy of the genus Chamaesyce SF Gray (Euphorbiaceae) in the Iberian Peninsula and the Balearic Islands. Collectanea Botanica, 21, 9-55. https://doi.org/10.3989/colle ctbot.1992.v21.92

Brochet, A.L., Guillemain, M., Fritz, H., Gauthier-Clerc, M. and Green, A.J. (2010) Plant dispersal by teal (Anas crecca) in the Camargue: duck guts are more important than their feet. Freshwater biology, 55(6), 1262-1273. https://doi.org/10.1111/j.1365-2427.2009.02350.x

Bojnanský, V. and Fargašová, A. (2007) Atlas of seeds and fruits of Central and East-European flora: The Carpathian Mountains region. Springer Science \& Business Media. 
Bouten, W., Baaij, E. W., Shamoun-Baranes, J. and Camphuysen, K. C. J. (2013). A flexible GPS tracking system for studying bird behaviour at multiple scales. J. Ornithol., 154(2), 571-580. https://doi. org/10.1007/s10336-012-0908-1

Bullock, J.M., González, L.M., Tamme, R., Götzenberger, L., White, S.M., Pärtel, M. et al (2017) A synthesis of empirical plant dispersal kernels. Journal of Ecology, 105(1), 6-19. https://doi. org/10.1111/1365-2745.12666

Calvino-Cancela, M. (2011) Gulls (Laridae) as frugivores and seed dispersers. Plant Ecology, 212(7), 1149-1157. https://doi.org/10.1007/ s11258-011-9894-2

Cappers, R.T., Bekker, R.M. and Jans, J.E. (2012) Digitale Zadenatlas van Nederland/digital seed atlas of the Netherlands. Volume 4. Barkhuis.

Carnicer, J., Jordano, P. and Melián, C.J. (2009) The temporal dynamics of resource use by frugivorous birds: a network approach. Ecology, 90(7), 1958-1970. https://doi.org/10.1890/07-1939.1

Castroviejo, S. (Ed.). (1998) Flora ibérica: plantas vasculares de la Península Ibérica e Islas Baleares. Editorial CSIC-CSIC Press.

Caughlin, T.T., Ferguson, J.M., Lichstein, J.W., Bunyavejchewin, S. and Levey, D.J. (2014) The importance of long-distance seed dispersal for the demography and distribution of a canopy tree species. Ecology, 95(4), 952-962. https://doi.org/10.1890/13-0580.1

Chauhan, B.S., Migo, T., Westerman, P.R. and Johnson, D.E. (2010) Postdispersal predation of weed seeds in rice fields. Weed Research, 50(6), 553-560. https://doi.org/10.1111/j.1365-3180.2010.00807.x

Chauhan, B.S., Gill, G.S. and Preston, C. (2006) Tillage system effects on weed ecology, herbicide activity and persistence: a review. Australian Journal of Experimental Agriculture, 46(12), 1557-1570. https://doi. org/10.1071/EA05291

Chen, S.C. and Moles, A.T. (2015) A mammoth mouthful? A test of the idea that larger animals ingest larger seeds. Global Ecology and Biogeography, 24, 1269-1280. https://doi.org/10.1111/geb.12346

Cope, T.A. and Stace, C.A. (1978) The Juncus bufonius L. aggregate in western Europe. Watsonia, 12, 113-128.

Corlett, R.T. and Westcott, D.A. (2013) Will plant movements keep up with climate change? Trends in Ecology \& Evolution, 28(8), 482-488. https://doi.org/10.1016/j.tree.2013.04.003

Costa-Pereira, R., Lucas, C., Crossa, M., Anderson, J.T., Albuquerque, B.W., Dary, E.P. et al (2018) Defaunation shadow on mutualistic interactions. Proceedings of the National Academy of Sciences of the United States of America, 115, E2673-E2675. https://doi.org/10.1073/ pnas.1801106115

Costea, M., El Miari, H., Laczkó, L., Fekete, R., Molnár, A.V., Lovas-Kiss, Á. et al (2019) The effect of gut passage by waterbirds on the seed coat and pericarp of diaspores lacking "external flesh": Evidence for widespread adaptation to endozoochory in angiosperms. PLoS One, 14(12), e0226551.

Cuba-Diaz, M., Troncoso, J.M., Cordero, C., Finot, V.L. and RondanelliReyes, M. (2013) Juncus bufonius, a new non-native vascular plant in King George Island, South Shetland Islands. Antarctic Science, 25, 385-386. https://doi.org/10.1017/S0954102012000958

Cummings, J.L., Handley, L.W., MacBryde, B., Tupper, S.K., Werner, S.J. and Byram, Z.J. (2008) Dispersal of viable row-crop seeds of commercial agriculture by farmland birds: implication for genetically modified crops. Environmental Biosafety Research, 7, 241-252.

Czarnecka, J.andKitowski, I. (2013) The white stork as an engineering species and seed dispersal vector when nesting in Poland. Annales Botanici Fennici 50(1-2), 1-13. Finnish Zoological and Botanical Publishing Board. https://www.jstor.org/stable/23728170

Davidson, N.C., Fluet-Chouinard, E. and Finlayson, C.M. (2018) Global extent and distribution of wetlands: trends and issues. Marine and Freshwater Research, 69, 620-627. https://doi.org/10.1071/ MF17019

Dinno, A. and Dinno, M.A. (2017) Package 'dunn. test'. CRAN Repos. doi, 10.
Falcón, W., Moll, D. and Hansen, D.M. (2020) Frugivory and seed dispersal by chelonians: A review and synthesis. Biological Reviews, 95(1), 142-166. https://doi.org/10.1111/brv.12558

Farmer, J.A., Webb, E.B., Pierce, R.A. and Bradley, K.W. (2017) Evaluating the potential for weed seed dispersal based on waterfowl consumption and seed viability. Pest management science, 73(12), 2592-2603. https://doi.org/10.1002/ps.4710

Flack, A., Fiedler, W., Blas, J., Pokrovsky, I., Kaatz, M., Mitropolsky, M. et al (2016) Costs of migratory decisions: A comparison across eight white stork populations. Science Advances, 2(1), e1500931. https:// doi.org/10.1126/sciadv.1500931

Green, A.J., Soons, M., Brochet, A.L. and Kleyheeg, E. (2016) Dispersal of plants by waterbirds. In: Şekercioğlu, C.H., Wenny, D.G., Whelan, C.J. (Eds.) Why Birds Matter: Avian Ecological Function and Ecosystem Services, p. 147.

Green, A.J., Bustamante, J., Janss, G.F.E., Fernández-Zamudio, R.andDíazPaniagua, C. (2018) Doñana Wetlands (Spain). In: Finlayson, C.M., Milton, G.R., Prentice, R.C. and Davidson, N.C. (Eds.) The Wetland Book: II: Distribution, Description and Conservation. Springer, pp. 1123-1136.

Gosper, C.R., Stansbury, C.D. and Vivian-Smith, G. (2005) Seed dispersal of fleshy-fruited invasive plants by birds: contributing factors and management options. Diversity and distributions, 11(6), 549-558. https://doi.org/10.1111/j.1366-9516.2005.00195.x

Heap, I.M. (2009) International survey of herbicide-resistant weeds. Available at: http://weedscience.org/summary/species.aspx

Heleno, R. and Vargas, P. (2015) How do islands become green? Global Ecology and Biogeography, 24(5), 518-526. https://doi.org/10.1111/ geb.12273

Hill, M.O., Mountford, J.O., Roy, D.B. and Bunce, R.G.H. (1999) ECOFACT $2 a$ Technical Annex-Ellenberg's indicator values for British plants. Institute of Terrestrial Ecology, p. 46.

Hsieh, T.C., Ma, K.H. and Chao, A. (2016) iNEXT: an R package for rarefaction and extrapolation of species diversity (Hill numbers). Methods in Ecology and Evolution, 7(12), 1451-1456. https://doi. org/10.1111/2041-210X.12613

Jordano, P. (1995) Angiosperm fleshy fruits and seed dispersers: a comparative analysis of adaptation and constraints in plant-animal Interactions. The American Naturalist, 145, 163-191. https://doi. org/10.1086/285735

Julve, P. (1998) ff.-Baseflor. Index botanique, écologique et chorologique de la flore de France. Version: 31/08/2010. Available at: http://perso. wanadoo.fr/philippe.julve/catminat.htm

Klaassen, R.H., Ens, B.J., Shamoun-Baranes, J., Exo, K.M. and Bairlein, F. (2012) Migration strategy of a flight generalist, the Lesser Blackbacked Gull Larus fuscus. Behavioral Ecology, 23(1), 58-68.

Kleyer, M., Bekker, R.M., Knevel, I.C., Bakker, J.P., Thompson, K., Sonnenschein, M. et al (2008) The LEDA Traitbase: a database of life-history traits of the Northwest European flora. Journal of Ecology, 96(6), 1266-1274. https://doi.org/10.1111/j.13652745.2008.01430.x

Kleyheeg, E., Fiedler, W., Safi, K., Waldenström, J., Wikelski, M. and van Toor, M.L. (2019) A comprehensive model for the quantitative estimation of seed dispersal by migratory mallards. Frontiers in Ecology and Evolution, 7, 40.

Kwieciński, Z., Kwiecińska, H., Ratajszczak, R., Ćwiertnia, P. and Tryjanowski, P. (2006) Digestive efficiency in captive white storks Ciconia ciconia. In: Tryjanowski, P., Sparks, T.H. and Jerzak, L. (eds.) White Stork Study in Poland: Biology, Ecology and Conservation. Bogucki Wydawnictwo Naukowe.

Li, S.S., Wei, S.H., Zuo, R.L., Wei, J.G. and Qiang, S. (2012) Changes in the weed seed bank over 9 consecutive years of rice-duck farming. Crop protection, 37, 42-50. https://doi.org/10.1016/j.cropro.2012.03.001

Löve, D. (1963) Dispersal and survival of plants. Pergamon Press, pp. 189-205. 
Lovas-Kiss, Á., Sánchez, M.I., Molnár, V.A., Valls, L., Armengol, X., Mesquita-Joanes, F. et al. (2018b) Crayfish invasion facilitates dispersal of plants and invertebrates by gulls. Freshwater Biology, 63(4), 392-404. https://doi.org/10.1111/fwb.13080

Lovas-Kiss, A., Vizi, B., Vincze, O., Molnar, A. and Green, A.J. (2018a) Endozoochory of aquatic ferns and angiosperms by mallards in Central Europe. Journal of Ecology, 106, 1714-1723.

Lovas-Kiss, Á., Sánchez, M.I., Wilkinson, D.M., Coughlan, N.E., Alves, J.A. and Green, A.J. (2019) Shorebirds as important vectors for plant dispersal in Europe. Ecography, 42(5), 956-967. https://doi.org/10.1111/ ecog.04065

Lovas-Kiss, Á., Vincze, O., Kleyheeg, E., Sramkó, G., Laczkó, L., Fekete, R. et al (2020) Seed mass, hardness, and phylogeny explain the potential for endozoochory by granivorous waterbirds. Ecology and Evolution 10, 1413-1424. https://doi.org/10.1002/ece3.5997

Magnusson, A., Skaug, H., Nielsen, A., Berg, C., Kristensen, K., Maechler, M.et al (2017) Package 'glmmTMB'. R Package Version 0.2. 0.

Martín-Vélez, V. (2021) Wintering gulls as key vectors for dispersal of seeds, nutrients and contaminants in Andalusia. PhD Thesis. Madrid, España: Universidad de Alcalá. Alcalá de Henares.

Martín-Vélez, V., Sánchez, M.I., Shamoun-Baranes, J., Thaxter, C.B., Stienen, E.W.M., Camphuysen, K.C.J. et al (2019) Quantifying nutrient inputs by gulls to a fluctuating lake, aided by movement ecology methods. Freshwater Biology, 64, 1821-1832.

Martín-Vélez, V., Mohring, B., van Leeuwen, C.H.A., Shamoun-Baranes, J., Thaxter, C.B., Baert, J.M. et al (2020) Functional connectivity network between terrestrial and aquatic habitats by a generalist waterbird, and implications for biovectoring. Science of the Total Environment, 705, 135886. https://doi.org/10.1016/j.scito tenv.2019.135886

Massemin-Challet, S.Y.L.V.I.E., Gendner, J.P., Samtmann, S., Pichegru, L., Wulgue, A. and Le Maho, Y. (2006) The effect of migration strategy and food availability on White Stork Ciconia ciconia breeding success. Ibis, 148(3), 503-508. https://doi. org/10.1111/j.1474-919X.2006.00550.x

Milotic, T. and Hoffmann, M. (2016) Cost or benefit for growth and flowering of seedlings and juvenile grassland plants in a dung environment. Plant Ecology, 217, 1025-1042. https://doi.org/10.1007/s1125 8-016-0629-2

Powers, K.D., Noble, R.E. and Chabreck, R.H. (1978) Seed distribution by waterfowl in southwestern Louisiana. Journal of Wildlife Management, 42, 598-605.

Ramo, C., Aguilera, E., Figuerola, J., Máñez, M. and Green, A.J. (2013) Long-term population trends of colonial wading birds breeding in Doñana (SW Spain) in relation to environmental and anthropogenic factors. Ardeola, 60(2), 305-326. https://doi.org/10.13157/ arla.60.2.2013.305

R Core Team (2018). R: A language and environment for statistical computing. Vienna, Austria: R Foundation for Statistical Computing. https:// www.R-project.org/.

Rendón, M.A., Green, A.J., Aguilera, E. and Almaraz, P. (2008) Status, distribution and long-term changes in the waterbird community wintering in Doñana, south-west Spain. Biological Conservation, 141(5), 1371-1388. https://doi.org/10.1016/j.biocon.2008.03.006

Reynolds, C. and Cumming, G.S. (2016) Seed traits and bird species influence the dispersal parameters of wetland plants. Freshwater Biology, 61(7), 1157-1170. https://doi.org/10.1111/fwb.12776

Sánchez, M.I., Green, A.J. and Castellanos, E.M. (2005) Seasonal variation in the diet of Redshank Tringa totanus in the Odiel Marshes, southwest Spain: a comparison of faecal and pellet analysis. Bird Study, 52(2), 210-216. https://doi.org/10.1080/0006365050 9461393

Sanders, H.L. (1968) Marine benthic diversity: a comparative study. The American Naturalist, 102(925), 243-282. https://doi. $\operatorname{org} / 10.1086 / 282541$
Sanz-Aguilar, A., Jovani, R., Melián, C.J., Pradel, R. and Tella, J.L. (2015) Multi-event capture-recapture analysis reveals individual foraging specialization in a generalist species. Ecology, 96(6), 1650-1660. https://doi.org/10.1890/14-0437.1

Sebastián-González, E., Lovas-Kiss, Á., Soons, M., van der Broek, B. and Green, A.J. (2020) Waterbird seed-dispersal networks are similarly nested but less modular than those of frugivorous birds, and not driven by functional traits. Functional Ecology, https://doi. org/10.1111/1365-2435.13657

Sesser, K.A., Iglecia, M., Reiter, M.E., Strum, K.M., Hickey, C.M., Kelsey, R. et al (2018) Waterbird response to variable-timing of drawdown in rice fields after winter-flooding. PLoS One, 13(10), e0204800. https://doi.org/10.1371/journal.pone.0204800

Soons, M.B., Brochet, A.L., Kleyheeg, E. and Green, A.J. (2016) Seed dispersal by dabbling ducks: an overlooked dispersal pathway for a broad spectrum of plant species. Journal of Ecology, 104(2), 443-455. https://doi.org/10.1111/1365-2745.12531

Tablado, Z., Tella, J.L., Sánchez-Zapata, J.A.andHiraldo, F. (2010). The paradox of the long-term positive effects of a North American crayfish on a European community of predators. Conservation Biology, 24(5), 1230-1238.

Tamme, R., Götzenberger, L., Zobel, M., Bullock, J.M., Hooftman, D.A., Kaasik, A. et al (2014) Predicting species' maximum dispersal distances from simple plant traits. Ecology, 95(2), 505-513. https://doi. org/10.1890/13-1000.1

Thomson, F.J., Moles, A.T., Auld, T.D., Ramp, D., Ren, S.Q. and Kingsford, R.T. (2010) Chasing the unknown: predicting seed dispersal mechanisms from plant traits. Journal of Ecology, 98, 1310-1318. https:// doi.org/10.1111/j.1365-2745.2010.01724.x

Thuiller, W., Albert, C., Araujo, M.B., Berry, P.M., Cabeza, M., Guisan, A. et al (2008) Predicting global change impacts on plant species' distributions: future challenges. Perspectives in Plant Ecology, Evolution and Systematics, 9(3-4), 137-152. https://doi.org/10.1016/j. ppees.2007.09.004

Toral, G.M., Aragonés, D., Bustamante, J. and Figuerola, J. (2011) Using Landsat images to map habitat availability for waterbirds in rice fields. Ibis, 153(4), 684-694. https://doi. org/10.1111/j.1474-919X.2011.01147.x

Toral, G.M. and Figuerola, J. (2010) Unraveling the importance of rice fields for waterbird populations in Europe. Biodiversity and Conservation, 19(12), 3459-3469. https://doi.org/10.1007/s1053 1-010-9907-9

Tsunamoto, Y., Naoe, S., Masaki, T. and Isagi, Y. (2020) Different contributions of birds and mammals to seed dispersal of a fleshy-fruited tree. Basic and Applied Ecology, 43, 66-75. https://doi.org/10.1016/j. baae.2019.07.005

van Leeuwen, C.H., Tella, J.L. and Green, A.J. (2020) Animal-mediated dispersal in understudied systems. Frontiers in Ecology and Evolution, 7, 508. https://doi.org/10.3389/fevo.2019.00508

Oksanen, J., Blanchet, F.G., Kindt, R., Legendre, P., Ohara, R.B., Simpson, G.L.et al (2010) Vegan: community ecology package. R package version 1.17-4. Avilable at: http://cran.r-project.org

Vázquez, D.P., Blüthgen, N., Cagnolo, L. and Chacoff, N.P. (2009) Uniting pattern and process in plant-animal mutualistic networks: a review. Annals of botany, 103(9), 1445-1457. https://doi.org/10.1093/aob/ mcp057

Vekemans, X. and Hardy, O.J. (2004) New insights from fine-scale spatial genetic structure analyses in plant populations. Molecular Ecology, 13(4), 921-935. https://doi.org/10.1046/j.1365-294X.2004.02076.x

Viana, D.S., Santamaría, L. and Figuerola, J. (2016) Migratory birds as global dispersal vectors-. Trends in Ecology \& Evolution, 31, 763-775.

Wang, Y.I., Naumann, U., Wright, S.T. and Warton, D.I. (2012) mvabundan $\mathrm{R}$ package for model-based analysis of multivariate abundance data. Methods in Ecology and Evolution, 3(3), 471-474. https://doi. org/10.1111/j.2041-210X.2012.00190.x 
Wenny, D.G., Sekercioglu, C., Cordeiro, N.J., Rogers, H.S. and Kelly, D. (2016) Seed dispersal by fruit-eating birds. In: Şekercioğlu, C.H., Wenny, D.G., Whelan, C.J. (Eds.) Why Birds Matter: Avian Ecological Function and Ecosystem services, pp. 107-145.

Wetlands International (2020) Waterbird Population Estimates. Retrieved from wpe.wetlands.org

Wilman, H., Belmaker, J., Simpson, J., De La Rosa, C., Rivadeneira, M.M. and Jetz, W. (2014) EltonTraits 1.0: Species-level foraging attributes of the world's birds and mammals: Ecological Archives E095-178. Ecology, 95(7), 2027. https://doi.org/10.1890/13-1917.1

\section{SUPPORTING INFORMATION}

Additional supporting information may be found online in the Supporting Information section.
Appendix S1. Information regarding Jaccard Index calculation

Appendix S2. Complete plant list found in vegetation transects and samples analysed

Appendix S3. Statistical results from mvabund package for every single plant species

How to cite this article: Martín-Vélez V, Lovas-Kiss Á, Sánchez MI, Green AJ. Endozoochory of the same community of plants lacking fleshy fruits by storks and gulls. J Veg Sci. 2021;32:e12967. https://doi.org/10.1111/jvs.12967 